\title{
BMJ Open Associations of behavioural risk factors and health status with changes in physical capability over 10 years of follow-up: the MRC National Survey of Health and Development
}

\author{
Rachel Cooper, Graciela Muniz-Terrera, Diana Kuh
}

To cite: Cooper R, MunizTerrera G, Kuh D.

Associations of behavioural risk factors and health status with changes in physical capability over 10 years of follow-up: the MRC National Survey of Health and Development. BMJ Open 2016;6:e00996.

doi:10.1136/bmjopen-2015009962

- Prepublication history and additional material is available. To view please visit the journal (http://dx.doi.org/ 10.1136/bmjopen-2015009962).

Received 10 September 2015 Revised 26 February 2016 Accepted 23 March 2016

MRC Unit for Lifelong Health and Ageing at UCL,

University College London, London, UK

Correspondence to Dr Rachel Cooper; rachel.cooper@ucl.ac.uk

\section{ABSTRACT}

Objectives: (1) To describe changes in objective measures of physical capability between ages 53 and 60-64 years; (2) to investigate the associations of behavioural risk factors (obesity, physical inactivity, smoking) and number of health conditions (range $0-4$ : hand osteoarthritis $(\mathrm{OA})$; knee $\mathrm{OA}$; severe respiratory symptoms; other disabling or life-threatening conditions (ie, cancer, cardiovascular disease, diabetes)) at age 53 years with these changes.

Design: Nationally representative prospective birth cohort study.

Setting: England, Scotland and Wales.

Participants: Up to 2093 men and women from the Medical Research Council National Survey of Health and Development, who have been followed-up since birth in 1946, and underwent physical capability assessments performed by nurses following standard protocols in 1999 and 2006-2010.

Main outcome measures: Grip strength and chair rise speed were assessed at ages 53 and 60-64 years. Four categories of change in grip strength and chair rise speed were identified: decline, stable high, stable low, a reference group who maintained physical capability within a 'normal' range.

Results: Less healthy behavioural risk scores and an increase in the number of health conditions experienced were associated in a stepwise fashion with increased risk of decline in physical capability, and also of having low levels at baseline and remaining low. For example, the sex and mutually adjusted relative-risk ratios $(95 \% \mathrm{Cl})$ of being in the stable low versus reference category of chair rise speed were 1.58 (1.35$1.86)$ and 1.97 (1.57-2.47) per 1 unit change in behavioural risk score and health indicator count, respectively.

Conclusions: These findings provide evidence of the associations of a range of modifiable factors with agerelated changes in physical capability. They suggest the need to target multiple risk factors at least as early as mid-life when aiming to promote maintenance and prevent decline in physical capability in later life.

\section{Strengths and limitations of this study}

- This study characterises age-related changes in objective measures of physical capability between mid-life and early old age, across a life stage when there may be more opportunity to effectively intervene to prevent decline and promote maintenance.

- This is the first study to examine the mutually adjusted associations of behavioural risk factors and indicators of health status with changes in objective measures of physical capability.

- Findings suggest modifiable targets for intervention in mid-life, which focus on the prevention of decline and the promotion of maintenance in physical capability.

- The study sample was selected at birth to be nationally representative, and after 64 years it remained so in many respects. However, only those participants who were assessed at ages 53 and 60-64 years could be included in analyses, and it was necessary to exclude people who had been assessed at age 53 years but subsequently died.

\section{INTRODUCTION}

Maintaining physical capability, the ability to perform the physical tasks of daily living, is an important component of healthy ageing. ${ }^{1}{ }^{2}$ However, age-related declines in physical capability are widely reported from mid-life onwards ${ }^{3-5}$ suggesting that opportunities for maintenance may be limited. An acknowledged limitation of cross-sectional data showing that older people have lower mean levels of physical capability than younger people on whom these reports are often based, ${ }^{6-9}$ is that they cannot distinguish age from cohort and period effects. Further, even when repeated data within individuals are available there is often a specific focus 
on modelling mean decline ${ }^{10-16}$ with methods employed that assume similar patterns of change for all. Thus interindividual differences in the patterns of within-individual change in physical capability observed over time may be overlooked. Where differences between individuals in the scale and direction of within-individual change in physical capability have been described, ${ }^{3} 1718$ these suggest that a significant proportion of older people may not be experiencing meaningful decline in any specified observation period.

In light of evidence that patterns of within-individual change in physical capability may be heterogeneous, consistent with recent findings for other healthy ageing phenotypes ${ }^{19}$ it seems plausible to distinguish four groups. Those experiencing decline in physical capability, those with relatively high levels at baseline which are maintained and those with relatively low levels at baseline who remain low may be compared and contrasted with those maintaining physical capability levels within a 'normal' range. Studying how these groups differ with respect to modifiable factors may present new opportunities for intervention focusing on the promotion of healthy ageing.

That a range of behavioural risk factors and indicators of health status are associated with physical capability and its age-related decline is well recognised. ${ }^{13}{ }^{20-24}$ However, a growing body of evidence highlights the benefits of considering the co-occurrence of these factors and examining their combined impact on different ageing phenotypes, ${ }^{25}$ including self-reported and performancebased measures of physical capability. ${ }^{26-30}$ However, few studies have assessed the mutually-adjusted associations of behavioural risk factors and health status together and none have related these to different patterns of change in objective measures of physical capability.

Using data from the Medical Research Council (MRC) National Survey of Health and Development (NSHD), a nationally representative British birth cohort study, the objectives of this paper were to: (1) describe the changes observed in objective measures of physical capability (grip strength and chair rise speed) from ages 53 to $60-64$ years and the variability between individuals in these within-individual changes; (2) identify four prespecified categories of change in physical capability and; (3) investigate the associations of behavioural risk factors and indicators of health status with these categories of change.

\section{MATERIALS AND METHODS}

The NSHD is a socially stratified sample of 5362 singleton births (2547 males and 2815 females) that took place in 1 week of March 1946 in mainland Britain, with regular follow-up across life. ${ }^{31}{ }^{32}$ During the two most recent waves of data collection, in 1999 (at 53 years) and 2006-2010 (at 60-64 years), physical capability was assessed using performance-based measures.

At age 53 years, 3035 participants were successfully contacted, of whom 2984 received a home visit from a trained nurse. At age 60-64 years, 2856 eligible participants (those known to be alive, living in England, Scotland or Wales, and who had not permanently refused to participate) were invited for assessment at one of six clinical research facilities (CRFs), or to be visited by a research nurse at home, of whom 2229 were assessed (1690 at a CRF and 539 at home). See online supplementary appendix figure 1 for reasons for losses to follow-up.

Relevant ethical approval was received; assessment in 1999 was approved by the North Thames Multi-Centre Research Ethics Committee, and in 2006-2010 by the Central Manchester Local Research Ethics Committee and the Scottish A Research Ethics Committee. All participants gave informed consent.

\section{Ascertainment of physical capability}

Grip strength and chair rise speed were assessed at ages 53 and 60-64 years by trained nurses using standardised protocols as described elsewhere ${ }^{33}$ and summarised here.

At both ages, grip strength was measured isometrically using a Nottingham electronic handgrip dynamometer. The dynamometers were calibrated at the start of testing using a back-loading rig, and are accurate, linear and stable to $\pm 0.5 \mathrm{~kg}{ }^{34}$ The intraparticipant retest variability for maximal voluntary tests of strength in those unused to such measurements is approximately $\pm 9 \% .{ }^{35}$ At age 53 years, four values (two in each hand), and at age 6064 years, six values (three in each hand) were recorded. To ensure comparability between ages, the highest value achieved at age 53 years and the highest of the first four values recorded at age 60-64 years were used in analyses. At both ages, the time taken to rise from a sitting to a standing position with straight back and legs, and then sit down again 10 times as fast as possible was measured using a stopwatch. The times recorded were used to calculate chair rise speed (ie, number of rises (ie, 10)/time taken (in minutes)). For both tests, nurses recorded if a study participant was unable or unwilling to perform the test, and the reason for this (eg, health reasons, technical problems).

Four categories of change in grip strength and chair rise speed were identified as follows: (1) sex-specific SD scores $($ mean $=0, \mathrm{SD}=1)$ of grip strength and chair rise speed at each age (based on the distributions at that age) were derived in the samples with valid measures at both ages $(\mathrm{n}=1896$ grip strength, $\mathrm{n}=1885$ chair rise speed); (2) each SD score was categorised: $<-1 \mathrm{SD}$; -1 to $1 \mathrm{SD} ;>1 \mathrm{SD}$; (3) the categorised SD scores for ages 53 and 60-64 years were cross-tabulated, and categories of change identified as shown in table 1 . These categories were: (1) reference (ie, maintained physical capability within 'normal' range); (2) decline; (3) stable high; (4) stable low. Participants with valid values at age 53 years who were unable to complete the test for health reasons at age 60-64 years were included in the 'decline' category $(\mathrm{n}=41$ grip strength, $\mathrm{n}=88$ chair rise speed), and participants who were unable to complete the test for 
Table 1 Four categories of change derived by cross-tabulating sex-specific SD scores for grip strength and chair rise speed at ages 53 and 60-64 years in the Medical Research Council National Survey of Health and Development

\begin{tabular}{llll}
\hline Grip strength/chair rise speed SD score at age & $60-64$ years & & \\
\cline { 2 - 3 } 53 years & $<-1 \mathrm{SD}$ & $-1 \mathrm{SD}$ to $1 \mathrm{SD}$ & $>1 \mathrm{SD}$ \\
\hline$<-1 \mathrm{SD}$ & 4. Stable low & 1. Reference & 1. Reference \\
$-1 \mathrm{SD}$ to $1 \mathrm{SD}$ & 2. Decline & 1. Reference & 1. Reference \\
$>1 \mathrm{SD}$ & 2. Decline & 2. Decline & 3. Stable high \\
\hline
\end{tabular}

Sex-specific SD scores calculated using the distributions of grip strength and chair rise speed at each age among the sample with valid measures at both ages.

health reasons at both ages were included in the 'stable low' category ( $\mathrm{n}=5$ grip strength, $\mathrm{n}=38$ chair rise speed).

\section{Explanatory factors}

To create a cumulative behavioural risk factor score, three behavioural risk factors assessed at age 53 years that were associated with physical capability at this age were selected a priori: overweight and obesity; physical inactivity; smoking. ${ }^{33}$ 36-38 Height $(\mathrm{cm})$ and weight $(\mathrm{kg})$ were measured by nurses, and body mass index (BMI) $\left(\mathrm{kg} / \mathrm{m}^{2}\right)$ was calculated. For those people with a valid weight measure but missing height $(n=5)$, height was imputed using a measure from age 43 years. BMI was categorised into three groups: normal weight $\left(<25 \mathrm{~kg} / \mathrm{m}^{2}\right) ; \quad$ overweight $\quad\left(25-29.99 \mathrm{~kg} / \mathrm{m}^{2}\right) ; \quad$ obese $\left(\geq 30 \mathrm{~kg} / \mathrm{m}^{2}\right)$. Participants were asked to report whether or not they had participated in any sports, vigorous leisure activities or exercises in their spare time, not including getting to and from work, in the past 4 weeks, and if so, on how many occasions they had done these activities. This was categorised into three groups: inactive (no participation); moderately active (participated 1-4 times); most active (participated $\geq 5$ times). Smoking status was categorised as: current; ex; never smoker. Each of these factors was coded: $0=$ most healthy (ie, normal weight, most active, and never smoker, respectively); $1=$ intermediate (ie, overweight, moderately active, and ex-smoker, respectively) and; 2=least healthy (ie, obese, inactive, smoker, respectively). The three factors were then summed to create a total score ranging from 0 (most healthy) to 6 (least healthy).

\section{Health status}

Four indicators of health status at age 53 years that were cross-sectionally associated with physical capability ${ }^{33}$ were selected a priori: hand osteoarthritis (OA); knee OA; severe respiratory symptoms and other disabling or lifethreatening conditions. During the home visit at 53 years, trained nurses conducted clinical examinations of the hands and knees using validated criteria. During assessment of the hands, the presence of Heberden nodes, Bouchard nodes and squaring at the carpometacarpal joint were identified, and hand OA was defined as involvement of at least one joint. ${ }^{39}$ Knee OA was defined using the American College of Rheumatology criteria for the clinical diagnosis of idiopathic knee OA, ${ }^{40}$ namely knee pain in either knee on most days for at least 1 month in the last year, and at least two of the following: stiffness, crepitus, bony tenderness and bony enlargement. ${ }^{41}$ Respiratory symptoms were assessed using the UK Medical Research Council's standardised questions. ${ }^{42} \mathrm{~A}$ group with the most severe symptoms was identified who reported one or more of the following: a wheezy or whistling chest most days or nights; usually bringing up phlegm or coughing in the morning or during the day or night in winter for at least 3 months each year; or more than one chest illness in the past 3 years that kept them off work or indoors for 1 week or more. Those participants who at 53 years reported cancer in the previous 10 years, diabetes at any time up to and including age 53 years, or cardiovascular disease (defined as having: a heart attack or stroke ever, aortic stenosis or valvular disease in the past 10 years, doctor-diagnosed angina or Rose angina grade I or II, or intermittent claudication), were categorised as having other potentially disabling or life-threatening conditions. To assess the cumulative influence of comorbidities, a variable was derived that indicated the number of health status indicators each participant reported ranging from 0 (no reported health problems) to 4 (all 4 indicators reported).

\section{Statistical analyses}

Descriptive analyses were used to explore the mean levels of grip strength and chair rise speed at ages 53 and 60-64 years in the total sample, and in each of the four categories of change. Latent change score models ${ }^{43} 44$ using the maximum data available provided an estimate of the between-individual variability in the level of within-individual change observed.

Using multinomial logistic regression models, the associations of the behavioural risk factor score and the health indicator count with the different categories of change (vs the reference group) in grip strength and chair rise speed were tested. Relative-risk ratios (RRR) were estimated for unit changes in the behavioural risk factor score and health indicator count with deviations from linearity formally tested to ensure that assumptions of linearity were met. Initial models were adjusted for sex, with sex interactions also formally tested. A subsequent model included mutual adjustment for behavioural risk and health status. Models were run on the samples with complete data on change and both sets of risk factors ( $\mathrm{N}=1906$, grip strength and $\mathrm{N}=1975$, chair rise speed). 
Sensitivity analyses were performed to test the sexadjusted associations of each component of the behavioural risk factor score and the health indicator count with changes in grip strength and chair rise speed.

\section{RESULTS}

Mean levels of grip strength and chair rise speed were lower at age 60-64 years than at 53 years in men and women (table 2). Latent change score models estimated mean changes in: grip strength $(\mathrm{kg})$ of $-3.23(95 \%$ CI -3.88 to -2.59$)$ for men and -2.07 ( -2.51 to -1.63$)$ for women; and chair rise speed (stands/minute) of -5.91 $(-6.40$ to -5.42$)$ for men and $-5.23(-5.71$ to -4.74$)$ for women. Estimates of variance and covariance in these models were statistically significant $(\mathrm{p}<0.001)$ (see online supplementary appendix 2) showing a high degree of between-individual variability in within-individual change. When changes in grip strength and chair rise speed were categorised into four groups, approximately $20 \%$ of participants were classified as showing clear evidence of decline, approximately $5 \%$ were classified as stable high, and a similar proportion as stable low (table 3 ).

Increases in the behavioural risk factor score and health indicator count were both associated with increased risk of decline in grip strength when compared with the reference category (table 4). These associations were maintained after mutual adjustment. Associations were also found between the behavioural risk factor score, health indicator count and risk of being in the stable low category. There was some evidence to suggest that poorer health status was more strongly associated with risk of being in the stable low category (RRR $=1.36$ (95\% CI 1.06 to 1.75$)$ ) than of being in the decline category ( $R R R=1.15$ (1.00 to 1.33)).

For chair rise speed, increases in the behavioural risk factor score and health indicator count were both associated with increased risks of being in the decline or stable low category, and with reduced risk of being in the stable high category when compared with the reference category. These associations were attenuated but maintained after mutual adjustment. Associations with risk of being in the stable high category appeared to be stronger for behavioural risk factors than for health status. On the basis of a qualitative assessment of the size of the effect estimates (table 4), there was also some evidence to suggest that the behavioural risk factor score and health indicator count were more strongly associated with risk of being in the stable low category, than with risk of being in the decline category.

In sensitivity analyses, similar patterns of association were found for the majority of individual components of

Table 2 Characteristics of the Medical Research Council National Survey of Health and Development stratified by sex (sample restricted to those with data on change in grip strength and/or chair rise speed (maximum N=2093)).

\begin{tabular}{|c|c|c|c|c|c|}
\hline & \multicolumn{2}{|l|}{ Men } & \multicolumn{2}{|c|}{ Women } & \multirow[b]{2}{*}{ p Value } \\
\hline & $\overline{\mathbf{N}^{*}}$ & Mean (SD) or \% & $\mathbf{N}^{*}$ & Mean (SD) or \% & \\
\hline \multicolumn{6}{|l|}{ Physical capability at ages 53 and 60-64 years } \\
\hline Grip strength at 53 years $(\mathrm{kg})$ & 958 & $47.8(12.1)$ & 1067 & $28.1(8.0)$ & $<0.001$ \\
\hline Grip strength at $60-64$ years $(\mathrm{kg})$ & 934 & $44.6(11.6)$ & 1020 & $26.0(7.4)$ & $<0.001$ \\
\hline Chair rise speed at 53 years (stands/min) & 939 & $32.1(10.2)$ & 1049 & $30.8(9.3)$ & 0.003 \\
\hline Chair rise speed at $60-64$ years (stands/min) & 919 & $26.4(7.2)$ & 1029 & $25.5(7.9)$ & 0.01 \\
\hline \multirow{2}{*}{\multicolumn{6}{|c|}{$\begin{array}{l}\text { Behavioural risk factors and indicators of health status at age } 53 \text { years } \\
\text { Body mass index (BMI) }\end{array}$}} \\
\hline & & & & & \\
\hline Obese & 983 & 20.2 & 1101 & 23.4 & $<0.001$ \\
\hline \multicolumn{6}{|l|}{ Physical activity } \\
\hline Inactive & 985 & 42.8 & 1108 & 45.4 & 0.22 \\
\hline \multicolumn{6}{|l|}{ Smoking status } \\
\hline Current smoker & 985 & 18.4 & 1108 & 19.3 & $<0.01$ \\
\hline Behavioural risk factor score (range 0-6) & 983 & $2.9(1.3)$ & 1101 & $2.8(1.5)$ & 0.06 \\
\hline Hand osteoarthritis & 985 & 18.9 & 1108 & 30.1 & $<0.001$ \\
\hline Knee osteoarthritis & 975 & 7.1 & 1092 & 12.2 & $<0.001$ \\
\hline Severe respiratory symptoms & 985 & 16.4 & 1107 & 16.9 & 0.74 \\
\hline Other disabling/life-threatening conditions $\ddagger$ & 984 & 8.5 & 1107 & 9.4 & 0.49 \\
\hline Health indicator count (range 0-4) & 974 & $0.5(0.7)$ & 1091 & $0.7(0.8)$ & $<0.001$ \\
\hline$\geq 1$ health indicator reported & & 40.6 & & 50.4 & \\
\hline \multicolumn{6}{|c|}{ 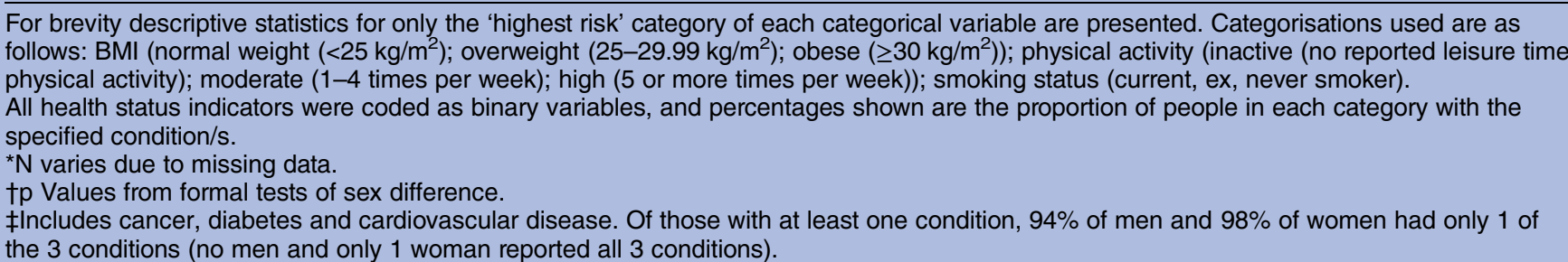 } \\
\hline
\end{tabular}


Table 3 Mean levels of grip strength and chair rise speed at ages 53 and 60-64 years in each category of change in the Medical Research Council National Survey of Health and Development

\begin{tabular}{|c|c|c|c|c|c|c|}
\hline & \multicolumn{3}{|l|}{ Men } & \multicolumn{3}{|l|}{ Women } \\
\hline & \multirow[b]{2}{*}{$\mathrm{N}^{\star}(\%)$} & \multicolumn{2}{|l|}{ Mean (SD) } & \multirow[b]{2}{*}{$\mathrm{N}^{*}(\%)$} & \multicolumn{2}{|l|}{ Mean (SD) } \\
\hline & & at 53 years & at $60-64$ years & & at 53 years & at $60-64$ years \\
\hline \multicolumn{7}{|c|}{ Grip strength (kg) } \\
\hline Reference & $649(70.5)$ & $46.1(9.6)$ & $46.6(8.5)$ & $688(67.3)$ & $26.5(5.9)$ & $27.3(5.8)$ \\
\hline Decline & $169(18.4)$ & $53.6(12.2)$ & $35.9(11.4)$ & 231 (22.6) & $31.6(8.3)$ & $20.5(6.5)$ \\
\hline Stable high & $53(5.8)$ & $68.1(6.5)$ & $64.7(7.2)$ & $54(5.3)$ & $41.9(8.4)$ & $38.8(4.1)$ \\
\hline Stable low & $49(5.3)$ & $28.6(6.3)$ & $27.2(4.3)$ & $49(4.8)$ & $16.8(2.5)$ & $15.5(2.6)$ \\
\hline \multicolumn{7}{|c|}{ Chair rise speed (stands/min) } \\
\hline Reference & $648(68.4)$ & $29.8(6.2)$ & $26.9(5.3)$ & $771(72.5)$ & $29.2(6.0)$ & $26.2(6.8)$ \\
\hline Decline & $195(20.6)$ & $36.6(13.5)$ & $21.6(5.9)$ & $202(19.0)$ & $35.8(12.8)$ & $21.3(6.9)$ \\
\hline Stable high & $56(5.9)$ & $51.1(7.9)$ & $42.0(6.2)$ & $37(3.5)$ & $50.4(7.8)$ & $42.0(8.4)$ \\
\hline Stable low & $49(5.2)$ & $18.7(2.3)$ & $16.7(2.0)$ & $53(5.0)$ & $17.8(2.9)$ & $15.1(2.5)$ \\
\hline
\end{tabular}

See table 1 for details of how categories are defined.

In total sample with valid measures at both ages, mean (SD) sex-specific values are as follows:

Grip strength $(\mathrm{kg})$ : men $(\mathrm{N}=908)$ : 53 years=47.9 (12.1); 60-64 years=44.7 (11.6); women $(\mathrm{N}=988)$ : 53 years=28.2 (7.9); 60-64 years=26.0 (7.4).

Chair rise speed (stands/min): men ( $\mathrm{N}=893)$ : 53 years=32.2 (10.2); 60-64 years=26.5 (7.2); women ( $\mathrm{N}=992): 53$ years=31.2 (9.2); $60-$ 64 years $=25.7(7.9)$.

${ }^{*}$ Total $\mathrm{N}$ in each category. Ns for presented means may vary due to inclusion in these categories of: (1) participants with valid values at 53 who were unable to complete the test for health reasons at 60-64 years in the 'evidence of decline' category ( $n=41$ for grip strength (12 men, 29 women), $\mathrm{n}=88$ for chair rise speed ( 37 men, 51 women)) and; (2) participants who were unable to complete the test for health reasons at both ages in the 'stable low' category ( $n=5$ for grip strength ( 0 men, 5 women), $n=38$ for chair rise speed (18 men, 20 women)).

the behavioural risk factor score and health indicator count (see online supplementary appendix 3), although some associations were weaker.

\section{DISCUSSION}

In a large nationally representative study, declines in mean levels of grip strength and chair rise speed between ages 53 and 60-64 years were observed. The changes in these summary statistics with age, disguised a large amount of variability between individuals in the levels of within-individual change experienced. In addition to those who had clearly declined, three other groups that appeared to have maintained their capability over time but had different baseline levels of capability and, hence, different health prospects, could be identified. There was evidence that people in each of these categories had different risk factor profiles. Less healthy behavioural risk scores and an increase in the number of health conditions experienced at baseline were both associated with increased risk of decline and of having low levels of capability at baseline and remaining low when compared with the reference group of participants who maintained physical capability within a 'normal' range. Those who had high levels of physical capability at baseline and retained these were more likely to have healthier behavioural risk scores and fewer health conditions than those in the reference group.

\section{Comparison with other studies}

The mean annual changes in grip strength observed in the NSHD were similar to those reported in a Finnish study at a similar age. ${ }^{14}$ Observed changes in mean levels of chair rise speed were slightly greater than expected, based on cross-sectional estimates. ${ }^{6} 7$ However, it has been shown that cross-sectional data may underestimate age-related change. ${ }^{11} 18$ That we found that the summary estimates mask significant between-individual variability in the levels of within-individual change experienced confirms findings from other studies that have described this. ${ }^{3} 1718$

These findings build on, and extend those from previous studies, that have explored the associations of behavioural risk factors and/or health status with physical capability. ${ }^{26-30}$ Like these studies, we also found evidence of dose-response effects when combining different behavioural risk factors in the same score, and when investigating number of comorbidities reported. However, this is the first study to examine the associations of both sets of factors with different patterns of change in objective measures of physical capability in mutually adjusted models.

\section{Explanation of findings}

Underlying explanations of the associations between each individual component of these scores and physical capability have been described previously. ${ }^{33}$ 36-38 Consistent with findings from other studies, ${ }^{25}$ clearer evidence of associations was found when using these composite scores than when examining each component separately, which is likely to be explained by the co-occurrence of these factors.

Behavioural risk factors and indicators of health status were associated not only with risk of decline but also with risk of being in the stable low and stable high categories. This is likely to be partially explained by the 


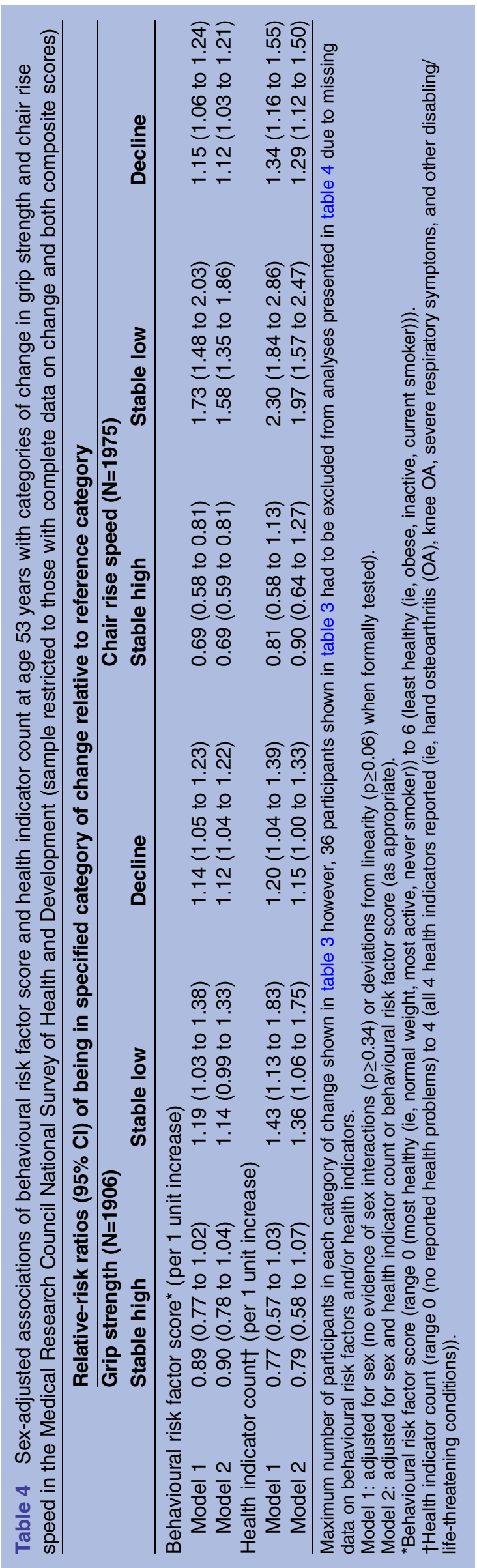

influence of behavioural risk factors and underlying disease processes on the development and maintenance of physical capability in early to mid-life as well as on age-related declines. That the health indicator count was more strongly associated with risk of being in the stable low category than in the decline category suggests that having low levels of physical capability in mid-life may be a manifestation of underlying disease processes that started earlier in life and may have influenced development. It also indicates that the negative impact on physical capability of conditions such as OA, usually reported in older populations, ${ }^{45}$ may already be manifest by mid-life.

\section{Methodological considerations}

A key strength of our analyses was the availability of data on within-individual change in two widely used objective measures of physical capability. As data were collected in mid-life and early old age, this allowed us to study changes across a life stage when there may be more opportunity to effectively intervene to prevent decline and promote maintenance. By studying change across this specific age period, we could also attempt to distinguish between two groups with low levels of physical capability in old age who will have followed different life course trajectories; those who had achieved relatively high levels of capability earlier in life but then experienced decline in early old age, and those who have experienced poor development (and/or an earlier onset of decline), and so have had relatively low levels of capability across a longer period (and so had less 'opportunity' to decline during the study observation period).

The method of categorising change in physical capability was selected a priori to capture these and other expected differences that may be meaningful in the context of healthy ageing. This approach was also used with the aim of avoiding or minimising the impact of some of the limitations inherent in modelling change continuously when data are only available at two time points, ${ }^{46} 47$ including regression to the mean, measurement error, practice effects and inability to identify the shape of change. While established methods of categorising change scores were considered, ${ }^{48}$ the strict criteria applied when using these other methods resulted in only those people with very high levels of absolute decline who were more likely to have had high levels of capability at baseline, being distinguished from everyone else. Further, these other methods resulted in the creation of a heterogeneous 'no decline' category which grouped together those with a wide range of different baseline levels of capability, including those with the highest and lowest levels, who have very different health prospects. The strengths of our approach are likely to outweigh limitations including potential misclassification and reduced statistical power (particularly to detect associations in the relatively small stable high and low groups). That the main findings were largely unchanged 
when models were rerun using an alternative method to identify the four categories of change (details available on request), supports this and suggests that our findings are robust.

The NSHD study sample was selected at birth to be nationally representative, and after 64 years, it remained so in many respects. ${ }^{49}$ However, the fact that only those participants who were assessed at ages 53 and 6064 years could be included in our analyses needs to be taken into account when interpreting findings. It is also necessary to consider that bias could have been introduced by the exclusion of people who had been assessed at age 53 years but subsequently died. Previous analyses in the NSHD have shown that those who had weaker grip strength and slower chair rise speed at 53 years had higher rates of all-cause mortality over 13 years of follow-up. ${ }^{50}$ However, a Finnish study applied methods to take account of the effect of this right censoring due to death when estimating annual changes in grip strength across adulthood. This study found little impact of applying this method on the estimates produced before age 65 years,${ }^{14}$ suggesting that exclusion of those participants who died between ages 53 and 60-64 years in our analyses is unlikely to have introduced significant bias.

In these analyses, we chose a priori to focus on three key behavioural risk factors (ie, physical inactivity, obesity and smoking). However, it is acknowledged that other behavioural risk factors including high alcohol intake and poor diet quality may also be important, and warrant investigation in future analyses.

\section{Implications}

Our finding of associations of a behavioural risk factor score and health indicator count with changes in physical capability provides evidence of the importance of the effects of both these sets of modifiable factors. It suggests the need to take a holistic approach to intervention and to target multiple risk factors when aiming to promote maintenance and prevent decline in physical capability. That these factors were associated not only with risk of decline but also with risk of being in the stable low category highlights the need to monitor physical capability in mid-life to identify opportunities for early intervention; opportunities may already have been missed if no action is taken until later in life.

\section{CONCLUSIONS}

This study has demonstrated that change in physical capability between mid-life and early old-age, is a heterogeneous experience. It suggests that age-related decline may not be entirely inevitable, and is potentially modifiable. That there was consistent evidence of associations between a behavioural risk factor score (incorporating obesity, smoking and inactivity) and a health indicator count (incorporating a range of potentially disabling health conditions) at mid-life with different patterns of change in physical capability suggests potential opportunities for intervention to prevent decline and promote maintenance of physical capability.

Acknowledgements The authors are grateful to NSHD study members for their continuing support. We thank members of the NSHD scientific and data collection teams who were involved in the NSHD data collection in 2006-2010 at the following centres: MRC Unit for Lifelong Health and Ageing at UCL; MRC Epidemiology Unit, University of Cambridge; MRC Lifecourse Epidemiology Unit, University of Southampton; MRC Human Nutrition Research, Cambridge; Wellcome Trust (WT) Clinical Research Facility (CRF) Manchester and the Department of Clinical Radiology at the Central Manchester University Hospitals NHS Foundation Trust; WTCRF and Medical Physics at the Western General Hospital in Edinburgh; WTCRF and the Department of Nuclear Medicine at University Hospital Birmingham; WTCRF and the Department of Nuclear Medicine at University College London Hospital; CRF and the Department of Medical Physics at the University Hospital of Wales; CRF and Twin Research Unit at St Thomas' Hospital London.

Contributors RC and DK conceived the idea for this study, developed the study objectives, and were responsible for the data collection. GM-T provided statistical advice. RC and GM-T undertook statistical analyses. All authors contributed to the interpretation of the data. RC drafted the article and all authors contributed to its critical revision, and provided final approval of the version to be published. RC is the guarantor and accepts full responsibility for the work and the conduct of the study, had access to the data, and controlled the decision to publish. All authors had full access to all the data (including statistical reports and tables) in the study, and can take responsibility for the integrity of the data and the accuracy of the data analysis.

Funding RC and DK are supported by the UK Medical Research Council (Programme code MC_UU_12019/4). GMT is supported by the National Institute on Aging of the National Institutes of Health under award number P01AG043362 for the Integrative Analysis of Longitudinal Studies of Aging (IALSA) research network. The MRC National Survey of Health and Development is funded by the UK Medical Research Council. The funders of the study had no role in the study design, data collection, data analysis, data interpretation, writing of the report or the decision to submit the article for publication.

Competing interests All authors have completed the ICMJE uniform disclosure form at http://www.icmje.org/coi_disclosure.pdf and declare: RC, GMT and DK received financial support from the UK Medical Research Council for the submitted work and GMT also received financial support from the US National Institute on Aging; no financial relationships with any organisations that might have an interest in the submitted work in the previous 3 years; no other relationships or activities that could appear to have influenced the submitted work.

Ethics approval Central Manchester Local Research Ethics Committee and the Scottish A Research Ethics Committee.

Provenance and peer review Not commissioned; externally peer reviewed.

Data sharing statement Data are available on request to the NSHD Data Sharing Committee. NSHD data sharing policies and processes meet the requirements and expectations of MRC policy on sharing of data from population and patient cohorts: http://www.mrc.ac.uk/research/ research-policy-ethics/data-sharing/policy/. Data requests should be submitted to mrclha.swiftinfo@ucl.ac.uk ; further details can be found at http://www. nshd.mrc.ac.uk/data.aspx. These policies and processes are in place to ensure that the use of data from this 70-year-old national birth cohort study is within the bounds of consent given previously by study members, complies with MRC guidance on ethics and research governance, and meets rigorous MRC data security standards.

Open Access This is an Open Access article distributed in accordance with the terms of the Creative Commons Attribution (CC BY 4.0) license, which permits others to distribute, remix, adapt and build upon this work, for commercial use, provided the original work is properly cited. See: http:// creativecommons.org/licenses/by/4.0/ 


\section{REFERENCES}

1. Kuh D, Karunananthan S, Bergman $\mathrm{H}$, et al. A life-course approach to healthy ageing: maintaining physical capability. Proc Nutr Soc 2014;73:237-48.

2. Kuh D, Richards M, Cooper R, et al. Life course epidemiology, ageing research, and maturing cohort studies: a dynamic combination for understanding healthy ageing. In: Kuh D, Cooper R, Hardy $\mathrm{R}$, et al. eds. A life course approach to healthy ageing. 1st edn. Oxford: Oxford University Press, 2014:3-15.

3. Kallman DA, Plato CC, Tobin JD. The role of muscle loss in the age-related decline of grip strength-ross-sectional and longitudinal perspectives. J Gerontol 1990;45:M82-8.

4. Metter EJ, Conwit R, Tobin J, et al. Age-associated loss of power and strength in the upper extremities in women and men. J Gerontol A Biol Sci Med Sci 1997;52:B267-76.

5. Nahhas RW, Choh AC, Lee M, et al. Bayesian longitudinal plateau model of adult grip strength. Am J Hum Biol 2010;22:648-56.

6. Cooper R, Hardy R, Aihie Sayer A, et al. Age and gender differences in physical capability levels from mid-life onwards: the harmonisation and meta-analysis of data from eight UK cohort studies. PLOS ONE 2011;6:e27899.

7. Keevil VL, Hayat S, Dalzell N, et al. The physical capability of community-based men and women from a British cohort: the European Prospective Investigation into Cancer (EPIC)-Norfolk study. BMC Geriatr 2013;13:93.

8. Kenny RA, Coen RF, Frewen J, et al. Normative values of cognitive and physical function in older adults: findings from the Irish Longitudinal Study on Ageing. J Am Geriatr Soc 2013;61(Suppl 2): S279-90.

9. Dodds RM, Syddall HE, Cooper R, et al. Grip strength across the life course: normative data from twelve British studies. PLOS ONE 2014;9:e113637.

10. Onder G, Penninx BW, Lapuerta $\mathrm{P}$, et al. Change in physical performance over time in older women: the women's health and aging study. J Gerontol A Biol Sci Med Sci 2002;57:M289-93.

11. Forrest KYZ, Zmuda JM, Cauley JA. Patterns and correlates of muscle strength loss in older women. Gerontology 2007;53:140-7.

12. Schaap LA, Pluijm SMF, Deeg DJH, et al. Low testosterone levels and decline in physical performance and muscle strength in older men: findings from two prospective cohort studies. Clin Endocrinol 2008;68:42-50.

13. Stenholm S, Tiainen K, Rantanen $\mathrm{T}$, et al. Long-term determinants of muscle strength decline: prospective evidence from the 22-year mini-Finland follow-up survey. J Am Geriatr Soc 2012;60:77-85.

14. Stenholm S, Härkänen $T$, Sainio $P$, et al. Long-term changes in handgrip strength in men and women-accounting the effect of right censoring due to death. J Gerontol A Biol Sci Med Sci 2012;67:1068-74.

15. Houston DK, Tooze JA, Neiberg $\mathrm{RH}$, et al. 25-hydroxyvitamin $\mathrm{D}$ status and change in physical performance and strength in older adults: the Health, Aging, and Body Composition Study. Am J Epidemiol 2012;176:1025-34.

16. Botoseneanu A, Allore HG, Gahbauer EA, et al. Long-term trajectories of lower extremity function in older adults: estimating gender differences while accounting for potential mortality bias. J Gerontol A Biol Sci Med Sci 2013;68:861-8.

17. Rantanen T, Masaki K, Foley D, et al. Grip strength changes over 27 yr in Japanese-American men. J Appl Physiol 1998;85:2047-53.

18. Hughes VA, Frontera WR, Wood M, et al. Longitudinal muscle strength changes in older adults: influence of muscle mass, physical activity, and health. J Gerontol A Biol Sci Med Sci 2001;56:B209-17.

19. Lowsky DJ, Olshansky SJ, Bhattacharya J, et al. Heterogeneity in healthy aging. J Gerontol A Biol Sci Med Sci 2014;69:640-9.

20. Guralnik JM, LaCroix AZ, Abbott RD, et al. Maintaining mobility in late life. I. Demographic characteristics and chronic conditions. Am J Epidemiol 1993;137:845-57.

21. LaCroix AZ, Guralnik JM, Berkman LF, et al. Maintaining mobility in late life. II. Smoking, alcohol consumption, physical activity, and body mass index. Am J Epidemiol 1993;137:858-69.

22. Stuck AE, Walthert JM, Nikolaus $T$, et al. Risk factors for functional status decline in community-living elderly people: a systematic literature review. Soc Sci Med 1999;48:445-69.

23. Schaap LA, Koster A, Visser M. Adiposity, muscle mass, and muscle strength in relation to functional decline in older persons. Epidemiol Rev 2013;35:51-65.

24. Lee CG, Schwartz AV, Yaffe K, et al. Changes in physical performance in older women according to presence and treatment of diabetes mellitus. J Am Geriatr Soc 2013;61:1872-8.

25. Sabia S, Singh-Manoux A, Hagger-Johnson G, et al. Influence of individual and combined healthy behaviours on successful aging. CMAJ 2012;184:1985-92.
26. Koster A, Penninx BW, Newman AB, et al. Lifestyle factors and ncident mobility limitation in obese and non-obese older adults. Obesity (Silver Spring) 2007;15:3122-32.

27. Liao WC, Li CR, Lin YC, et al. Healthy behaviors and onset of functional disability in older adults: results of a national longitudinal study. J Am Geriatr Soc 2011;59:200-6.

28. Artaud F, Dugravot A, Sabia S, et al. Unhealthy behaviours and disability in older adults: three-City Dijon cohort study. BMJ 2013;347:f4240.

29. Robinson SM, Jameson KA, Syddall HE, et al. Clustering of lifestyle risk factors and poor physical function in older adults: the Hertfordshire cohort study. J Am Geriatr Soc 2013;61:1684-91.

30. Stenholm S, Westerlund H, Head J, et al. Comorbidity and functional trajectories from midlife to old age: the Health and Retirement Study. $J$ Gerontol A Biol Sci Med Sci 2015;70:332-8.

31. Wadsworth M, Kuh D, Richards M, et al. Cohort profile: the 1946 National Birth Cohort (MRC National Survey of Health and Development). Int J Epidemiol 2006;35:49-54.

32. Kuh D, Pierce M, Adams J, et al. Cohort profile: updating the cohort profile for the MRC National Survey of Health and Development: a new clinic-based data collection for ageing research. Int J Epidemiol 2011;40:e1-9.

33. Kuh D, Bassey EJ, Butterworth S, et al. Grip strength, postural control, and functional leg power in a representative cohort of British men and women: associations with physical activity, health status, and socioeconomic conditions. J Gerontol A Biol Sci Med Sci 2005;60:224-31.

34. Kuh D, Hardy R, Butterworth S, et al. Developmental origins of midlife grip strength: findings from a birth cohort study. J Gerontol A Biol Sci Med Sci 2006;61:702-6.

35. Bassey EJ. Longitudinal changes in selected physical capabilities: muscle strength, flexibility and body size. Age Ageing 1998;27(Suppl 3):12-16.

36. Hardy R, Cooper R, Aihie Sayer A, et al. Body mass index, muscle strength and physical performance in older adults from eight cohort studies: the HALCyon programme. PLOS ONE 2013;8:e56483.

37. Cooper R, Mishra GD, Kuh D. Physical activity across adulthood and physical performance in midlife: findings from a British Birth Cohort. Am J Prev Med 2011;41:376-84.

38. Strand $\mathrm{BH}$, Mishra G, Kuh D, et al. Smoking history and physical performance in midlife: results from the British 1946 birth cohort. $J$ Gerontol Med Sci 2011;66A:142-9.

39. Sayer AA, Poole J, Cox V, et al. Weight from birth to 53 years: a longitudinal study of the influence on clinical hand osteoarthritis. Arthritis Rheum 2003;48:1030-3.

40. Altman R, Asch E, Bloch D, et al. Development of criteria for the classification and reporting of osteoarthritis. Classification of osteoarthritis of the knee. Diagnostic and Therapeutic Criteria Committee of the American Rheumatism Association. Arthritis Rheum 1986;29:1039-49.

41. Wills AK, Black S, Cooper R, et al. Life course body mass index and risk of knee osteoarthritis at the age of 53 years: evidence from the 1946 British birth cohort study. Ann Rheum Dis 2012;71:655-60.

42. Medical Research Council. Questionnaire on respiratory symptoms and instructions for interviewers. London: Medical Research Council, 1976.

43. Hamagami F, McArdle JJ. Advanced studies of individual differences linear dynamic models for longitudinal data analysis. In: Marcoulides GA, Schumacker RE, eds. New developments and techniques in structural equation modeling. Mahwah, NJ: Lawrence Erlbaum Associates Inc, 2001:203-46.

44. McArdle JJ. A latent difference score approach to longitudinal dynamic structural analysis. In: Cudeck R, du Toit S, Sörbom D, eds. Structural equation modeling: present and future. Lincolnwood, IL: Scientific Software International, Inc, 2001:341-80.

45. Edwards $\mathrm{MH}$, van der Pas S, Denkinger MD, et al. Relationships between physical performance and knee and hip osteoarthritis: findings from the European Project on Osteoarthritis (EPOSA). Age Ageing 2014;43:806-13.

46. Singer JD, Willett JB. Applied longitudinal data analysis: Modeling change and event occurrence. 1st edn. Oxford: Oxford University Press, 2003.

47. Fitzmaurice $\mathrm{G}$. A conundrum in the analysis of change. Nutrition 2001;17:360-1.

48. Frerichs RJ, Tuokko HA. A comparison of methods for measuring cognitive change in older adults. Arch Clin Neuropsychol 2005;20:321-33.

49. Stafford M, Black S, Shah I, et al. Using a birth cohort to study ageing: representativeness and response rates in The National Survey of Health and Development. Eur J Ageing 2013;10:145-57.

50. Cooper R, Strand BH, Hardy R, et al. Physical capability in mid-life and survival over 13 years of follow-up: British birth cohort study. BMJ 2014;348:g2219. 
Correction: Associations of behavioural risk factors and

health status with changes in physical capability over

10 years of follow-up: the MRC National Survey of Health

and Development

Cooper R, Muniz-Terrera G, Kuh D. Associations of behavioural risk factors and health status with changes in physical capability over 10 years of follow-up: the MRC National Survey of Health and Development. BMJ Open 2016;6:e009962. doi: 10.1136/ bmjopen-2015-009962

The first line of the methods reads:

'The NSHD is a socially stratified sample of 5362 singleton births (2547 males and 2815 females)'

however, this should have read:

'The NSHD is a socially stratified sample of 5362 singleton births (2815 males and 2547 females)'.

Open Access This is an Open Access article distributed in accordance with the terms of the Creative Commons Attribution (CC BY 4.0) license, which permits others to distribute, remix, adapt and build upon this work, for commercial use, provided the original work is properly cited. See: http://creativecommons.org/licenses/by/4.0/

C Article author(s) (or their employer(s) unless otherwise stated in the text of the article) 2018. All rights reserved. No commercial use is permitted unless otherwise expressly granted.

BMJ Open 2018;8:e009962corr1. doi:10.1136/bmjopen-2015-009962corr1

A Check for updates 